\title{
Effect of Maternal Linguistic Input Type on Communicative Behaviors and Language Ability of 18- to 24-Month-Old Toddlers
}

\author{
Gyu Ri Kima, Hee Ran Lee ${ }^{\mathrm{b}}$ \\ ${ }^{a}$ Department of Speech and Hearing Therapy, Graduate School of Catholic University of Pusan, Busan, Korea \\ ${ }^{b}$ Department of Speech and Hearing Therapy, Catholic University of Pusan, Busan, Korea
}

Correspondence: Hee Ran Lee, PhD

Department of Speech and Hearing Therapy,

Catholic University of Pusan, 57 Oryundae-ro,

Geumjeong-gu, Busan 46252, Korea

Tel: +82-51-510-0841

Fax: +82-51-510-0848

E-mail: hrlee@cup.ac.kr

Received: January 5, 2017

Revised: February 14, 2017

Accepted: February 17, 2017

This work is based on a part of the first author's master's thesis from Catholic University of Pusan.
Objectives: The study examined communicative behaviors and language abilities of 18- to 24-month-old toddlers according to maternal linguistic input types. Methods: The study was conducted with 40 participants: 20 toddlers age 18-24 months whose overall development was within a normal range for DEP (Developmental Assessment for the Early Intervention Program Planning) and -1 standard deviation for SELSI (Sequenced Language scale for Infants), and 20 mothers of the toddlers. We analyzed a 10-minute video that recorded interactive play and reading with the toddlers and mothers and performed SELSI and K M-B CDI (Korea MacArthur-Bate Communicative Development Inventory) to evaluate the toddlers'language abilities. Results: First, there was no significant difference between communicative behaviors and language abilities according to mothers' linguistic input types in play and reading situations. However, we were able to distinguish maternal linguistic input types as a referential-expressive type in an interaction situation with the toddlers and mothers. Second, we examined a relation between communicative behaviors and language abilities according to maternal linguistic input types. Conclusion: The study reveals that appropriate harmony brings a positive effect on communicative behaviors and language abilities, as opposed to only one type of input (either the mother referential type where the linguistic input type is oriented for mothers or the toddler-oriented expressive type). The study demonstrates clinical significance by suggesting the necessity of parental education to promote communication and language development for toddlers and mothers must be included in the early selection, diagnosis, and intervention for toddlers at risk for language disorders.

Keywords: Maternal linguistic input, Communicative behavior, Language ability, Language development
영유아 시기에는 인지와 언어 및 의사소통에서 급속한 변화가 이루어지며, 부모와의 상호작용을 통해 사회적인 관계 형성의 기초 를 마련해 나간다. 또한 유아는 말 산출 이전 시기부터 스스로를 둘 러싼 환경과 적극적으로 의사소통을 시도하며, 지속적으로 자신의 의도를 표현하게 되는데, 이러한 과정들은 이후 기능적인 언어발달 을 지원하는 다양한 능력들로 발전하게 된다. 특히, 공동 주의와 몸 짓 표현 같은 특성들은 다른 사람과의 상호작용을 유지하거나 관 심을 유도하기 위해 사용되는 의사소통 행동으로써 이후 언어발달
에 기초가 되는 요인 중 하나이다(Toth, Munson, Meltzoff, \& Dawson, 2006).

유아의 언어발달에 영향을 미치는 다양한 변인들에는 신체 운 동 기능, 인지, 기질 등 개인의 내적 요인과 주양육자의 역할을 강조 한 환경적 요인을 들 수 있다(Hong, 2009; Lee, 2011). 유아는 다양 한 초기 의사소통 기능들을 주양육자인 어머니를 통해 습득하고 발달시켜 나가게 되는데, 이러한 의사소통 행동의 대다수는 이후 에 언어적인 형태로 나타난다. 실제로, 어머니는 유아와의 상호작 
Gyu Ri Kim, et al. • Effective of Language Input Type on Communicative and Language Ability of Toddlers

용에서 사람이나 대상에 대해 이름을 붙여주거나 유아의 말을 수 정하고 정보를 얻기 위한 질문을 하는 등 유아를 대화에 참여시키 고, 언어적 반응을 촉진하기 위한 여러 가지 전략과 더불어 다양한 상황 맥락을 활용하기도 한다. 연구에 따르면, 어머니들은 일상적 인 육아 상황, 자유 놀이 상황, 책 읽기 상황 순으로 유아에게 점점 더 복잡한수준으로 말을 하였다(Lee \& Seol, 2012; Park \& Jo, 2008; Sung, 2003). 즉, 상황 맥락에 따라 유아의 행동에 대해 반응하는 방식에 차이가 있었으며, 이에 따른 유아의 반응도 매우 다양하게 나타났다. 또한 유아의 반응에 따라 자신의 반응을 적절하게 조절 하며, 이러한 상호작용 방식이 서로에게 긍정적 영향을 미치기도 한다. 이는 어머니의 반응성으로 정의할 수 있는데, 아이의 상태나 요구에 대해 즉각적으로 인식하여 민감하고 적절하게 반응해주는 동시에 정서적으로 자녀의 행동을 존중하는 부모의 태도를 말한 다(Choi \& Hyun, 2002; Ko \& Kim, 2015).

이처럼 영유아의 언어 및 의사소통 발달과 관련하여 어머니의 상 호작용 방식과 언어적 입력의 중요성이 강조되면서 국내에서도 이 에 대한 연구들이 다양하게 이루어졌다. 연구들은 대부분 어머니 와 유아의 상호작용 상황에서 언어 자극의 양이나 유형, 혹은 언어 전략이 유아의 언어 습득에 미치는 영향에 관한 것이었다(ChangSong, 2004; Kim \& Kwak, 2010; Lee, Lee, \& Chang, 2004; Lee \& Seol, 2012; Park \& Jo, 2008; Sung, 2003). 어머니의 언어적 입력은 분명 유아의 어휘발달에 도움을 줄 수 있으나, 유아의 언어발달 수 준과 무관하게 단순히 입력의 양이 많다는 것이 유아의 어휘발달 에 도움이 되는가는 분명치 않다. 유아의 언어와 의사소통 발달에 서는 어머니와 주고 받는 상호작용의 양과 더불어 질 또한 무엇보 다 중요하다(Ludden, 2016). 유아의 어휘발달에 도움을 주는 어머 니의 상호작용 관련 변인들을 살펴본 Hong (2009)에 따르면, 어머 니의 언어자극 형태가 질적 측면에서 변화할 때 표현어휘 증가에 더욱 효과적이라고 하였다.

어머니가 유아의 언어적 행동을 촉진하기 위하여 사용하는 여러 가지 전략들이 항상 동일한 빈도로 사용되는 것은 아니다. 어머니 는 유아를 상호작용에 참여시키고, 언어행동을 촉진하기 위해 아 기지향어(infant direct speech)와 같은 다양한 소통 전략과 맥락을 활용한다. 이러한 어머니의 언어적 상호작용 형태는 상당히 가변적 으로 나타나기도 하는데, 이는 개인의 성격과 언어특성, 인지 양식 같은 내적 요인에 따라 다양하게 나타날 수 있다(Della Corte, Benedict, \& Klein, 1983; Lee et al., 2004; Vaala et al., 2010). 각 개인은 선 호하는 특정한 인지 양식이 있으며, 이에 따라 인식, 기억, 사고 및 문제 해결과 같은 인지적 행동을 수행할 때 개인이 반응하는 양식 은 다를 수 있다(Shin \& Kim, 2013). 이는 인지 구조에 따라 언어를
습득하고 사용하는 방법에도 개인차가 존재하고, 의사소통 상황 에서 어머니 각각의 언어적 입력 유형이 다를 수 있음을 의미한다. 어머니의 언어입력 유형과 형식은 유아의 언어발달과 소통 방식에 매우 직접적으로 영향을 미칠 수 있으므로 연구자들의 관심이 좀 더 집중될 필요가 있을 것이다. 예를 들어, Ludden (2016)도 언급하 고 있듯이, 명령하기(instructions)와 금지하기(prohibitions)로 이뤄 지는 부모와 아동 간의 일상적인 대화 주고받기는 아동의 행동을 조정하는 데는 매우 필요하지만, 어휘발달을 성공적으로 이끄는 것 은 어머니가 공동 주의 대상에 이름대기를 하거나, 그것에 대해 설 명해주는 것과 같은 서술적 대화(descriptive talk)이다.

반면, 아동의 의사소통 유형에 관한 고전적 분류로 Nelson (1973) 은 대상에 관심이 많고 일반적인 명사를 주로 사용하는 아동을 '지 시적(referential child)' 유형으로, 자기 지향적이며 정서상태나 사 회적 표현과 관련된 어휘를 주로 사용하는 아동을 “표현적(expressive child)' 유형으로 분류하였다.

한편, Klein (1980)은 어머니의 태도와 아동의 의사소통 특성과 의 관계를 살펴보기 위하여 식사와 놀이 상황에서 이들 간의 상호 작용을 분석하였다. 아동의 특성에 따라 어머니의 태도에 차이가 나타났는데, 표현적인 아동의 어머니들보다 지시적인 아동의 어머 니들은 명사나 대상에 대한 언급을 더 많이 사용하였으며, 놀이보 다는 식사 상황에서 강화와 반복이 많이 나타났다고 한다. 즉, 어머 니와 유아가 선호하는 인지적 행동에 근거한 의사소통적 반응 유 형이 매우상호작용적임을 확인할 수 있다.

이후 Della Corte 등(1983)은 Nelson (1973)의 기준을 바탕으로 초기 어휘습득 특성에 따라 아동들을 지시적(referential) 유형과 표현적(expressive) 유형으로 구분하여 어머니의 말하기 특성을 구 체적으로 분석하였는데, 모든 범주에서 언급되는 명사의 양이 풍 부한 집단과 개인적인 어휘나 정서 상태, 사회적 관계를 표현하는 어휘습득이 풍부한 두 집단으로 확연히 구분되었다고 한다. 이에 따라 전자를 대상에 근거한 객체 지향적(object-oriented) 특성을 지닌 지시적 집단으로, 후자를 자기 지향적(self-oriented) 특성으 로 언어를 습득하는 표현적 집단으로 정의 하였다. 흥미로운 점은 두 집단의 어머니가 빈번하게 사용하는 의사소통 유형에서도 차이 를 보였는데, 지시적 아동의 어머니는 아동이 관심을 기울이는 대 상, 동작, 감정과 관련한 겉모습 묘사가 많았던 반면, 표현적인 아동 의 어머니는 아동의 행동이나 언어 표현을 직접적으로 표현하는 경 우가 많았다고보고하였다.

이처럼 어머니의 인지 양식에 근거한 의사소통은 아동의 발달 수준 및 어휘 특성을 반영하고 발달을 촉진한다(Kitamura \& Burnham, 2003). 실제로 자녀와 일상적인 상호작용을 하는 동안 부모가 
아동의 발달에 적합한 방식으로 반응적 상호작용 전략을 사용하 는 것은 아동의 일상에서 관찰할 수 있는 주의 집중(attention), 지 속성(persistence), 시작하기(initiation) 또는 공동 주의(joint attention)와 같은 초기 의사소통 행동을 촉진할 수 있다고 한다(Kim \& Mahoney, 2004). 따라서 앞서 지시적 유형과 표현적 유형으로 구분 되었던 아동의 의사소통 유형은 곧, 어머니의 의사소통 유형에 반 영될 수 있을 것이다. 즉, 어머니의 의사소통 유형 역시, 객체지향적 인 경우에는 이 객체가 대상 또는 어머니의 의도가 보다 많이 반영 된 소통 유형임을 가정할 수 있을 것이다. 또한 부모와 아동의 상호 작용 상황에서 의사소통 행동과 언어발달의 주체는 아동이므로 부모의 상호작용이 아동을 지향한 경우에는 개인적 어휘나 정서와 사회적 관계를 표현하는 자기지향적인 표현적 유형으로 볼 수 있을 것이다. 본 연구에서는 이와 같은 선행연구들을 토대로 영유아기 언어발달의 촉진과 지연을 결정짓는 어머니의 의사소통 특성을 분 석하여 유아에게 적절하고 질적으로 풍부한 언어적 자극을 제공하 도록 하는 근거를 마련하고자 하였다. 특히, 유아의 발달적 예후를 예측하며 언어장애위험군 유아의 조기 선별과 중재에도 긍정적인 도움을 줄 수 있는 기초자료로써의 부모-아동 상호작용 특성 분석 이 보다 다양하게 시도될 필요가 있음을 선행연구 분석을 통해 확 인할 수 있었다.

따라서 본 연구에서는 초기 언어 및 의사소통 발달에 직접적인 영향을 미치는 어머니의 언어적 입력 유형을 구분해봄으로써 그에 따른 아동의 의사소통 행동 특성과 언어능력 간의 차이와 관계를 살펴보고자하였다.

\section{연구 방법}

\section{연구대상}

본 연구는 부산광역시에 거주하는 $18-24$ 개월 일반 유아 26 명과 그 어머니 26 명, 총 52 명을 대상으로 하였다. 분석 절차에 따라 어머 니의 언어적 입력 유형을 지시적 집단과 표현적 집단으로 구분하는 과정에서 어머니의 요구하기와 설명하기 비율을 비교하였을 때 두 유형 간 비율 차이가 최소 $10 \%$ 이하인 4 명 아동과 어머니를 제외하 여 실제 분석 대상은 유아 20 명과 그 어머니 20 명으로 총 40 명이 연 구 대상이었다.

유아는 (1) 주양육자로부터 신체, 인지, 언어 및 정서.행동의 문제 가 없다고 보고되고, (2) 영아선별 교육진단검사 개정판(Developmental Assessment for the Early Intervention Program Planning, $\mathrm{DEP}$; Jang, Seo, \& Ha, 2011) 결과, 대근육과 소근육, 사회정서, 인 지, 그리고 기본 생활 항목이 정상발달에 속하며, (3) 영유아언어발
Table 1. Characteristics of participants $(\mathrm{N}=20)$

\begin{tabular}{lc}
\hline Characteristic & Value \\
\hline Chronological age (mo) & $20.80(1.99)$ \\
DEP & \\
Gross motor (\%ile) & $73.41(11.91)$ \\
Fine motor (\%ile) & $66.29(16.82)$ \\
Social emotion (\%ile) & $68.45(17.83)$ \\
Cognition (\%ile) & $81.46(12.32)$ \\
SELSI & \\
Receptive language (raw score) & $64.00(29.26)$ \\
Expressive language (raw score) & $50.75(28.89)$ \\
Total language & $56.12(25.33)$ \\
\hline
\end{tabular}

Values are presented as mean (SD).

$\mathrm{DEP}=$ Developmental Assessment for the Early Intervention Program (Jang, Seo, \& Ha, 2011); SELSI=Sequenced Language scale for Infants (Kim, Kim, Yoon, \& Kim, 2003).

달검사(Sequenced Language Scale for Infants, SELSI; Kim, Kim, Yoon, \& Kim, 2003)결과 수용 및 표현언어 점수가 -1 표준편차 이 상에 해당하는 유아로 선정하였다. 어머니는 (1) 유아의 주양육자 로, (2) 연령은 20-30대에 속하며, (3) 학력은 전문대졸 이상의 어머 니를 대상으로 선정하였다(Table 1).

\section{연구도구}

어머니의 언어적 입력 유형 분석

어머니의 언어적 입력 유형을 구분하기 위한 의사소통 특성 분 석을 위해 Della Corte 등(1983)과 Lee 등(2004)의 연구를 참조 및 수정하여 사용하였다(Appendix 1). Della Corte 등(1983)은 어머니 의 의사소통 유형을 명명하기(labelling), 정보 요구하기(request information), 제안하기(suggestion), 지시하기 (prescriptives), 금지하 기 (proscriptives), 음운적 수정(phonological corrections), 지시물 수정(referential corrections), 서술(description), 변형된 서술(displaced speech), 관습적인 사회적 표현(conventional social expressions), 사회적 놀이(social play), 간투사(fillers)로 나누어 분석하였 다. 한편, Lee 등(2004)은 어머니의 의사소통 유형을 주의환기, 설명 하기, 지시하기, 질문하기, 피드백의 다섯 가지의 범주로 나누어 구 분하였다. 본 연구에서 분석을 위해 적용한 각 의사소통 유형의 조 작적 정의는 다음과 같다.

(1) 주의환기: 유아의 주의를 끌기 위한 행동으로, 어머니가 유아 의 이름을 부르거나 ‘이거(여기) 봐라'와같은 지시를 포함.

(2) 명명하기: 사람이나 대상 또는 동작 및 상황의 이름을 말하거 나 붙여주는 것이며, 지시적인 대명사와 함께 사용될 수 있음. (3) 요구하기: 유아에게 반응을 이끌어내는 것으로 정보를 요구 하거나 직접적인 행동 또는 언어적 표현을 요청하거나 지시하 는 행동. 
Gyu Ri Kim, et al. • Effective of Language Input Type on Communicative and Language Ability of Toddlers

(4) 설명하기: 즉각적인 상황에서 어머니가 대상이나 유아의 행 동, 감정 그리고 주관적인 생각 또는 사실을 표현해주거나 과 거나 미래의 사건을 서술해주는 것을 포함.

(5) 피드백: 유아의 말이나 행동에 대해 반응해주는 것으로 칭찬, 대답, 명료화요구, 확인, 모방, 수정 등을 포함.

(6) 표현하기: 사회적인 상황에서 사용하는 관습적인 표현을 말 하는 것으로 '고마워', '미안해' 같은 표현들을 포함.

위와 같은 의사소통 유형의 조작적 정의를 토대로 어머니의 언어 적 입력 유형을 '지시적(referential)' 유형과 '표현적(expressive)' 유 형의 두 가지로 구분하고자 하였다. Della Corte 등(1983)은 아동이 대상을 지향하는(object-oriented) 어휘의 양이 풍부할 경우 지시 적 유형으로, 의사소통의 주체인 자기 자신의 개인적인 표현이나 정 서 상태, 사회적 관계와 관련한 표현이 풍부한 경우 자기 지향적 (self-oriented)으로 언어를 습득하는 표현적 유형으로 구분하였다. 이러한 선행연구를 토대로 본 연구에서는 어머니가 주도적으로 유 아의 언어나 행동을 결정짓는 어머니 중심(mother oriented)적인 의사소통 유형인 주의환기, 명명하기, 요구하기와 같이 비율이 높 은 경우 '지시적 유형'으로 정의 하였다. 반면에 설명하기와 피드백, 그리고 표현하기는 의사소통 행동과 언어발달의 주체인 유아의 행 동이나 언어를 어머니가 해석해주는 유아를 지향하는(child oriented) 형태이다. 따라서 설명하기, 피드백, 표현하기의 비율이 높은 경우 ‘표현적 유형'으로 구분하였다(Kim, Lee, \& Lee, 2015; Park \& Jo, 2008; Lee \& Seol, 2012).

먼저, 어머니의 전체 발화에서 위의 조작적 정의에 따라 여섯 가 지 의사소통 유형의 빈도를 측정한 뒤 전체 발화수로 나누어 각 의 사소통 유형 비율을 산출하였다. 이를 토대로 어머니의 언어적 입 력 유형을 구분하기 위한 지표로 지시적 유형에서 가장 두드러지는 요구하기를, 표현적 유형에서는 설명하기로 정하고 요구하기와 설 명하기의 비율을 각각 비교하였다. 요구하기와 설명하기의 비율을 비교하였을 때, 두 유형의 비율 간 차이가 최소 $10 \%$ 이상 나타나면서 요구하기의 비율이 높은 경우 지시적인 유형으로, 설명하기의 비율 이 높은 경우 표현적인 유형으로 구분하였다(Table 2). 이러한 분석 절차는 언어발달전문가이면서 1 급 언어재활사인 언어병리학과 교 수 2 인에게 분석 타당성과 비율 기준을 검증 받은 후 진행하였다.

\section{유아의 의사소통 행동 분석}

본 연구에서는 유아의 의사소통 행동을 분석하기 위하여 Lee와 Seol (2012)의 의사소통 행동 기준을 사용하였다(Appendix 2). 이 기준은 Sénéchal, Cornell과 Broda (1995)의 연구에 제시된 유아의 의사소통 행동에 ‘무반응’을 추가하여 총 여섯 가지 유형으로 구분
Table 2. Mother's language inputs

\begin{tabular}{lcc}
\hline & Referential type ( $\mathrm{N}=10)$ & Expressive type $(\mathrm{N}=10)$ \\
\hline Attention & $8.70(3.95)$ & $4.70(3.40)$ \\
Naming & $26.2(21.50)$ & $12.90(13.55)$ \\
Instruction & $102.2(32.36)$ & $92.90(25.79)$ \\
Description & $80.2(29.60)$ & $111.50(22.86)$ \\
Feedback & $22.70(15.69)$ & $47.80(30.13)$ \\
Expression & $2.90(3.93)$ & $6.20(4.95)$ \\
\hline
\end{tabular}

Values are presented as mean (SD).

하고 있다. 본 연구에서 채택한 ‘언급하기’, ‘요구하기’ , ‘모방하기', ‘질 문하기', '반응하기', '무반응' 유형에 대한 조작적 정의는 다음과 같 다.

(1) 언급하기: 대상이나 사물의 이름을 말하거나 주관적인 생각, 사실을 표현하는 행동

(2) 요구하기: 필요한 사물이나 행동을 요구하는 언어적 또는 비 언어적인 행동.

(3) 모방하기: 어머니의 발화를 완전하게 혹은 부분적으로 따라 하는 행동.

(4) 질문하기: 어머니의 대답이나 반응을 요구하는 언어적 또는 비언어적인 행동들을 포함.

(5) 반응하기: 어머니의 언어적 혹은 비언어적인 행동에 대한 유 아의 반응을 포함.

(6) 무반응: 어머니의 행동에 대하여 유아가 반응하지 않는 경우 를 포함.

유아의 의사소통 행동은 언어적인 행동과 비언어적인 행동을 모 두 포함하여 분석하였다.

\section{유아의 어휘력}

유아의 어휘력을 평가하기 위하여 공식 검사인 한국판 맥아더베이츠 의사소통발달평가(Korea MacArthur-Bate Communicative Development Inventory, K M-B CDI; Pae \& Kwak, 2011)를 실 시하였다. K M-B CDI는 어머니 보고를 통해 영유아시기(8-36개 월)의 어휘능력, 제스처, 놀이 그리고 문법 수준을 파악할 수 있으 며, 영아용(8-17개월 수준)과 유아용(18-36개월 수준)으로 구분되 는데, 본 연구에서는 유아용을 사용하였다.

타당도

어머니의 언어적 입력 유형과 유아의 의사소통 행동을 분석하는 기준이 적합한지에 대한 내용타당도를 검증하기 위해 두 명의 전문 가에게 평가를 받았다. 두 명의 전문가는 언어병리학을 전공한 1 급 
언어재활사 1 명과 언어치료학과 대학원생으로 3 년 이상의 언어치 료 현장 경력이 있는 언어재활사 1 명으로 하였다.

내용타당도는 본 연구에서 제시한 어머니의 언어적 입력 유형과 유아의 의사소통 행동을 분석하는 기준들에 대한 조작적 정의를 전문가가 읽고 채점하도록 하였으며, Likert 5점 척도로 구성하였 다. 내용타당도 검증 결과, 두 전문가 모두 내용타당도 평가지에 제 시된 분석 기준의 전체 항목을 5 점으로 평가하였다.

\section{연구절차}

예비연구

본 연구를 수행하기 전에 연구 과제의 내용 및 실시 방법이 적합 한지 알아보기 위하여 18-24개월 유아 5명을 대상으로 예비 연구 를 진행하였다. 기존 선행연구(Kim et al., 2015; Lee et al., 2004)에 따라 놀이와 책 읽기 상황에서 연구자가 직접 선택한 장난감과 책 을 유아와 어머니에게 제공하였다. 그러나 익숙하지 않은 놀잇감을 사용하게 하여 유아의 흥미를 유발하는 데 시간이 소요되었고, 익 숙한 장난감을 사용할 때와 비교하였을 때 어머니-유아 상호작용 의 질적인 면에서 차이가 나타났음을 확인하였다.

또한 어머니와 유아가 40 분간 상호작용을 하도록 지시하였으나 아직 어린 연령의 유아들이 이 시간 동안 부모와 지속적으로 상호 작용을 하기에 어려움이 있는 것으로 관찰되었다. 따라서 이와 같 은 예비연구 결과를 토대로, 본 연구에서는 실제 어머니와 유아가 평소 자주 사용하는 장난감과 책을 사용하도록 수정하고, 상호작 용 시간을 20 분으로 수정하였다. 또한 예비 연구를 거쳐 최종 선정 한 상황 맥락, 진행 방법과 과제의 내용을 언어병리학을 전공한 1 급 언어재활사 1 명과 임상경력 3 년의 언어재활사 1 명과 검토하였으며, 그 결과를 반영하여 본 실험을 진행하였다.

\section{자료 수집}

먼저, 연구 참여자를 모집하는 과정에서 유아와 어머니 간의 의 사소통 상황을 녹화하여 분석하는 본 연구의 절차를 설명하고 이 에 동의한 대상자들에게 본 연구를 진행하였다. 전화로 검사의 내 용과 진행 방법, 소요 시간에 관하여 설명한 후에 시간 약속을 정하 고 연구자가 직접 가정으로 방문하여 자료를 수집하였다. 연구자 는 어머니가 검사의 항목과 주의사항에 관하여 이해할 수 있도록 충분히 설명한 후에 유아의 연령 부분을 표시한 DEP, SELSI, KM-B $\mathrm{CDI}$ 평가지를 제공하였다. 유아가 해당되는 문항에 어머니가 직접 표시하도록 하였으며, 이해하지 못하는 부분은 연구자가 한 번 더 설명한 후에 표시하도록 하였다.

부모보고평가 실시 후 어머니와 유아의 상호작용 장면을 녹화하
였다. 어머니와 유아들의 상호작용이 주로 자유놀이와 책 읽기 상 황에서 이루어지고, 상호작용 상황에 따라 의사소통 유형이 달라 질 수 있다는 기존 연구(Lee et al., 2004)에 따라 놀이 상황과 책 읽 기 상황에서 자료를 수집하였다. 어머니에게 유아와 함께 평소처럼 자연스럽게 상호작용하도록 안내하였으며, 놀이와 책 읽기 활동의 진행 순서는 제약하지 않았다. 상호작용 도구는 어머니가 자유롭 게 선택하도록 하였으며, 유아가 평소에 자주 사용하고 좋아하는 장난감이나책을 사용하도록 허용하였다.

자료는 약 20 분 내외의 시간 동안 수집하였고, 모든 자료는 연구 자의 휴대폰을 이용하여 녹화하였다.

\section{자료분석}

모든 자료분석은 녹화 후 1-2일 이내에 실시하였다. 어머니와 유 아의 의사소통 상황을 녹화한 전체 자료 중에서 놀이의 시작과 끝 부분에 해당하는 앞 뒤 5-10분씩을 제외하고 상호작용이 활발하 게 진행되는 10 분만을 발췌하여 분석하였다(Kim \& Kwak, 2010). 어머니의 언어적 입력 유형에는 구어적인 행동만을 포함하고 유아 의 의사소통 행동은 구어와 비구어적인 행동을 모두 포함하여 놀 이 상황과 책 읽기 상황을 모두 전사하였다. 어머니의 언어적 입력 유형과 영유아의 의사소통 행동은 모두 빈도를 측정한 후 전체 발화 로 나누어 비율을 산출하였다. 어머니의 언어적 입력 유형은 Della Corte 등(1983)과 Lee 등(2004)의 기준을 참조 및 수정하여 분석하 였으며, 유아의 의사소통 행동은 Lee와 Seol (2012)의 기준을 토대 로 분석하였다.

\section{신뢰도}

부모보고에 의한 평가가 갖는 오류를 최소화하기 위하여 검사재검사 신뢰도를 검증하였다. 실험 4-5일 이후에 5명의 어머니에게 SELSI와 K M-B CDI의 재평가를 실시하여 문항에 대한 일관성을 살펴보았다. 전화상황에서 어머니가 표시한 항목에 대하여 연구자 가 질문한 후 어머니가 대답하는 방식으로 진행하였으며, 일치하지 않는 항목은 SELSI는 모두 ‘아니요’로, K M-B CDI는 표현어휘수의 측정치에서 제외하였다. 그 결과 검사-재검사 신뢰도는 $98.2 \%$ 로 측 정되었다.

자료 분석에 대한 신뢰도 검증을 위하여 본 연구의 연구자 1 명과 언어치료 임상경력 3년 이상으로 언어병리학을 전공하고 있는 석 사과정 대학원생 간의 검사자 간 일치율을 산출하였다. 그 결과 어 머니의 언어적 입력 유형에 대한 신뢰도는 $97.1 \%$, 유아의 의사소통 행동에 대한 신뢰도는 $94.6 \%$ 로 측정되었다. 
Gyu Ri Kim, et al. • Effective of Language Input Type on Communicative and Language Ability of Toddlers

\section{통계분석}

어머니의 언어적 입력 유형에 따른 유아의 의사소통 행동과 언어 능력은 독립표본 $t$-검정을 실시하여 분석하였다. 또한 어머니의 언어 적 입력 유형에 따른 유아의 의사소통 행동과 언어능력 간의 Pearson 상관분석을 실시하였다. 모든 통계처리는 IBM SPSS Statistics 21.0 프로그램을 사용하여 분석하였다.

\section{연구 결과}

\section{어머니의 언어적 입력 유형에 따른 유아의 의사소통 행동과 언어능력의 차이 비교}

먼저, 어머니의 언어적 입력 유형 집단 별 유아의 의사소통 행동 특성을 분석한 결과를 Table 3에 제시하였다. 지시적 어머니의 유 아들이 보인 의사소통 행동 특성은 반응하기 > 언급하기 > 무반응 $>$ 요구하기>모방하기>질문하기 순이었으며, 표현적 어머니 유아 들은 반응하기 > 언급하기 > 요구하기 > 무반응 > 모방하기 > 질문하 기 순이었다. 반응하기는 두 집단 유아들 모두에게서 가장 높은 빈 도의 의사소통 행동이었으나 표현적 어머니 아동에게서 좀 더 두드

Table 3. Child's communicative behaviors

\begin{tabular}{lcc}
\hline & Referential type $(\mathrm{N}=10)$ & Expressive type $(\mathrm{N}=10)$ \\
\hline Mention & $35.40(25.40)$ & $38.60(24.66)$ \\
Demand & $6.70(4.02)$ & $15.70(10.10)$ \\
Imitation & $3.70(5.19)$ & $10.10(16.87)$ \\
Question & $3.70(8.90)$ & $1.80(2.56)$ \\
Reaction & $45.80(18.45)$ & $50.70(27.36)$ \\
Reactionless & $9.00(10.47)$ & $15.70(13.67)$ \\
\hline
\end{tabular}

Values are presented as mean (SD).
러졌으며, 무반응 역시 표현적 어머니 아동에게서 좀 더 높게 나타 났다. 언급하기 역시 두 집단 모두에서 반응하기 다음으로 빈도가 높았음을 확인할 수 있었다.

어머니의 언어적 입력 유형 집단별 유아의 전체 의사소통 행동과 언어능력의 차이에 대한 기술 통계 결과는 Table 4 와 같다. 지시적 인 유형보다 표현적 유형 어머니의 유아가 전체적으로 더 높은 빈 도의 의사소통 행동을 보였다. 그러나, 독립표본 $t$-검정을 실시한 결 과에서는 두 측정치 간에 통계적으로 유의한 차이를 보이지 않았 다. 유아의 언어능력 분석을 위해 살펴본 SELSI 점수에서는 지시적 유형 어머니의 유아가 높은 점수를 보였고, 이러한 차이는 통계적 으로도 유의미하였다 $(t=1.254, p<.05)$. 반면, $\mathrm{K} \mathrm{M-B} \mathrm{CDI는} \mathrm{표현}$ 적 유형 어머니의 유아가 높은 점수를 보였지만, 통계적으로 유의 미한차이는 아니었다.

\section{어머니의 언어적 입력 유형에 따른 유아의 의사소통 행동과 언어능력 간의 상관}

지시적 유형 어머니와 유아의 의사소통 행동 및 언어능력 간의 상관 지시적인 어머니의 언어적 입력 유형에 따른 유아의 의사소통 행

Table 4. Comparison of groups by mother's language input

\begin{tabular}{lccc}
\hline & $\begin{array}{c}\text { Referential type } \\
(\mathrm{N}=10)\end{array}$ & $\begin{array}{c}\text { Expressive type } \\
(\mathrm{N}=10)\end{array}$ & $t$ \\
\hline Communicative behaviors & $104.30(46.70)$ & $132.60(56.6)$ & -1.218 \\
SELSI & $83.55(70.34)$ & $53.50(28.21)$ & $1.254^{*}$ \\
K M-B CDI & $32.35(22.80)$ & $43.00(28.42)$ & -.933 \\
\hline
\end{tabular}

Values are presented as mean (SD).

SELSI= Sequenced Language scale for Infants (Kim, Kim, Yoon, \& Kim, 2003); K M-B $\mathrm{CDI}=$ Korean MacArthur-Bates Communicative Development Inventories (Pae \& Kwak, 2011).

${ }^{*} p<.05$.

Table 5. Correlation between referential type and communicative behavior and language

\begin{tabular}{|c|c|c|c|c|c|c|}
\hline & \multicolumn{6}{|c|}{ Referential type } \\
\hline & Attention & Naming & Instruction & Description & Feedback & Expression \\
\hline \multicolumn{7}{|c|}{ Child communicative behavior } \\
\hline Mention & -.076 & -.029 & .370 & .301 & .332 & -.078 \\
\hline Demand & -.433 & -.441 & .287 & .193 & -.237 & .213 \\
\hline Imitation & -.219 & .088 & .479 & .537 & .609 & -.026 \\
\hline Question & .117 & .111 & .269 & .406 & .335 & -.095 \\
\hline Reaction & -.501 & -.283 & $.744^{*}$ & .585 & .179 & $.710^{*}$ \\
\hline Reactionless & .321 & .349 & -.207 & -.317 & .074 & -.116 \\
\hline \multicolumn{7}{|l|}{ Language ability } \\
\hline SELSI & -.274 & -.298 & -.386 & -.047 & -.443 & -.235 \\
\hline KM-BCDI & -.223 & -.299 & .406 & .560 & .377 & .414 \\
\hline
\end{tabular}

SELSI=Sequenced Language scale for Infants (Kim, Kim, Yoon, \& Kim, 2003); K M-B CDI= Korean MacArthur-Bates Communicative Development Inventories (Pae \& Kwak, 2011).

${ }^{*} p<.05$. 
Table 6. Correlation between expressive type and communicative behavior and language

\begin{tabular}{|c|c|c|c|c|c|c|}
\hline & & & Exp & ype & & \\
\hline & Attention & Naming & Instruction & Description & Feedback & Expression \\
\hline Child communic & & & & & & \\
\hline Mention & -.311 & .267 & $.635^{*}$ & .166 & $.692^{*}$ & -.578 \\
\hline Demand & .520 & -.436 & .063 & $.657^{*}$ & .425 & .177 \\
\hline Imitation & .367 & .356 & .342 & .624 & .326 & -.043 \\
\hline Question & -.591 & -.329 & .190 & -.190 & .151 & -.414 \\
\hline Reaction & .220 & .153 & $.805^{* *}$ & $.725^{*}$ & .589 & -.160 \\
\hline Reactionless & $.676^{*}$ & -.297 & -.438 & .299 & -.344 & $.897^{* *}$ \\
\hline Language abilit & & & & & & \\
\hline SELSI & $-.676^{*}$ & -.348 & .311 & -.348 & .044 & .044 \\
\hline K M-B CDI & -.088 & -.088 & .327 & .117 & -.044 & -.380 \\
\hline
\end{tabular}

SELSI=Sequenced Language scale for Infants (Kim, Kim, Yoon, \& Kim, 2003); K M-B CDI=Korean MacArthur-Bates Communicative Development Inventories (Pae \& Kwak, 2011).

${ }^{*} p<.05,{ }^{* *} p<.01$.

동과 언어능력 간의 상관관계를 분석한 결과, 어머니의 지시하기와 유아의 반응하기 간의 상관 계수는 .744, 어머니의 표현하기와 유아 의 반응하기의 상관 계수는 .710으로 유의수준 .05 수준에서 상관 이 있는 것으로 나타났다(Table 5).

표현적 유형 어머니와 유아의 의사소통 행동 및 언어능력 간의 상관

표현적 유형 어머니의 언어적 입력에 따른 유아의 의사소통 행동 과 언어능력 간의 상관관계를 분석한 결과, 어머니의 주의환기와 무반응 간의 상관은 .676, 지시하기와 유아의 언급하기는 .635로 나 타났다. 또한 어머니의 지시하기와 반응하기 간에는 .805 , 어머니의 설명하기와 유아의 요구하기 간에는 .657, 설명하기와 반응하기는 .725 , 피드백과 언급하기는 .692로 나타났으며 표현하기와 무반응 은 .897로 유의수준.05와 .01수준에서 상관이 있는 것으로 나타났 다(Table 6). 또한 표현적인 어머니의 언어적 입력 유형과 유아의 SELSI 간의 상관계수는 -.676으로 유의수준 .05수준에서 부적 상 관이 있는 것으로 나타났다.

\section{논의 및 결론}

본 연구에서는 놀이와 책 읽기의 상호작용 맥락에서 어머니의 언 어적 입력 유형에 따른 18-24개월 유아의 의사소통 행동과 언어능 력을 비교, 분석하였다.

연구 결과 첫째, 어머니의 언어적 입력 유형에 따른 유아의 의사 소통 행동의 차이를 비교한 결과 유의미한 차이가 나타나지 않았 다. 그러나 제시된 상호작용 상황에서 어머니가 선호하고 빈번하게 사용하는 언어적 입력 유형이 비교적 두드러졌음을 확인할 수 있었 다. 즉, 언어적 입력 유형과 아동이 선호하는 의사소통 형태가 있지
만 이들이 상황 맥락에 따라 상당히 가변적으로 나타나는 것으로 해석된다. 지시적, 표현적으로 구분된 언어적 입력 유형에 따른 유 아의 의사소통 행동 빈도 간에는 차이를 보였는데, 표현적 유형 어 머니의 유아가 지시적 유형 어머니의 유아보다 평균 점수가 더 높았 다. 이는 표현적 어머니가 좀 더 유아에게 조율된 언어 자극을 제시 한다는 것을 시사하며, 상호작용 상황에서 어머니가 유아의 의사 소통 의도를 읽고 이에 수반적으로 반응하는 것이 양육자와 유아 의 의사소통을 성공적으로 이끌고(Kim \& Kwak, 2010), 이러한 성 공 경험이 축적될수록 유아의 언어능력에 긍정적인 영향을 미치는 것으로 해석할 수 있었다.

반면, 어머니의 언어적 입력 유형에 따른 유아의 언어능력을 비 교한 결과, SELSI 점수에서 지시적 유형 어머니의 유아가 높은 점수 를 보였고, 이러한 차이는 통계적으로도 유의미하였다. 이러한 차 이에 대해서는 여러 가지 해석이 가능하겠지만, 지시적인 유형 어머 니의 경우 아동을 향해 어머니가 주도적으로 상호작용을 이끌어나 가면서, 유아에게 말을 많이 하며 유아의 행동과 언어적 반응을 직 접적으로 요구하는 명령이 많았다. 따라서 유아는 상호작용 상황 에서 공동 주의, 대답하기, 다시 말하기, 명명하기 등 자신의 언어를 사용하는 기회가 증가하였고 이것이 이러한 공식 검사의 점수에 영 향을 미친 것으로 해석할 수 있었다.

둘째, 어머니의 언어적 입력 유형에 따라 유아의 의사소통 행동 이 어떠한 상관을 보이는지 살펴본 결과, 먼저 지시적 유형 어머니 와 유아의 의사소통 행동은 지시하기-반응하기, 표현하기-반응하 기에서 상관이 나타났다. 어머니의 언어적 입력 유형 가운데 지시하 기는 상호작용 상황에서 어머니가 유아에게 정보나 행동, 언어적 표현을 요구하는 상호작용 방식이다. 이는 어머니가 유아의 반응을 직접적으로 이끌어내는 의사소통 방식으로, 유아는 어머니의 요구 
에 따라 상황 맥락에 적절한 행동 또는 언어적 표현을 산출하는 반 응이 증가하는 것으로 해석할 수 있다. 또한 본 연구에서 표현하기 는 사회적인 상황에서 사용하는 관습적인 표현들로 정의하였으며, 의사 전달 과정에서 사용되는 언어나 동작, 동요 등 보편적, 관습적 으로 기호화된 모든 종류의 전달을 포함하였다. 지시적 유형의 어 머니에게서 가장 빈번하게 나타난 관습적인 표현은 인사와 동요로, 어머니가 표현하기 전략을 사용하면 유아는 인사를 하거나 동요에 알맞은 제스처를 사용하면서 반응하는 모습을 보였다. 인사나 동 요 표현의 경우 일상 생활 속에서 이미 상호작용의 수단으로 반복 적으로 사용한 특성이 있으므로 유아의 자발적인 반응 빈도가 증 가하는 것으로 해석된다.

다음으로 표현적 유형의 어머니와 유아의 의사소통 행동 간의 관계를 살펴보았을 때, 주의환기-무반응, 지시하기-언급하기, 지시 하기-반응하기, 설명하기-요구하기, 설명하기-반응하기, 피드백-언 급하기, 표현하기-무반응에서 상관이 나타났다. 우선, 의사소통 행 동 유형 가운데 주의환기는 의사소통을 시작하거나 상호작용 맥락 을 전환할 때 주로 어머니가 중심이 되어 일방적으로 사용한다. 또 한 어머니가 유아의 주의를 끌기 위하여 언어와 행동을 제한하여 집중을 유도하거나 요구하는 행동이다. 유아는 이러한 주의환기를 통해 놀이에 참여하고 능동적으로 초기 의사소통 능력을 발달시 켜 나간다. 본 연구에서 특히 주목할 만한 점은 어머니의 주의환기 와 유아의 무반응이 정적 상관관계를 보였다는 결과이다. 어머니들 은 유아가 놀이에 참여하도록 요구하면서 주의환기를 사용하기도 하였지만, 유아가 산만하거나 어머니의 의도대로 상호작용이 이루 어지지 않는 경우 유아의 행동을 제지하기 위하여 더 많이 사용하 는 경향이 있었다. 따라서 의사소통 상황에서 맥락을 고려하지 않 고 반복적으로 주의환기를 사용하는 경우에는 이것이 유아에게 적절한 언어적 자극의 형태가 되기 어려운 경우도 있음을 알 수 있 었다. 어머니와 유아 간에 공동 주의가 충분히 이루어진 후 해석이 가능한 형태로 언어적 자극이 제공될 때 유아가 적절한 언어 및 의 사소통 반응을 나타낼 수 있을 것이기 때문이다. 또한 표현적 유형 어머니의 지시하기와 유아의 언급하기, 반응하기가 정적인 상관을 보이는 것은, 어머니가 직접적으로 유아에게 질문과 관련한 대상 또는 상황에 대한 언급을 요구하여 유아에게 반응할 기회를 보다 많이 제공하기 때문인 것으로 해석할 수 있다.

어머니의 설명하기와 유아의 요구하기, 반응하기 간의 정적 상관 을 살펴보면, 설명하기는 어머니가 유아의 행동이나 상황, 감정들 을 묘사해주는 것으로, 어머니가 사용하는 언어적 표현들은 유아 의 의사소통 행동을 지지하는 역할을 한다. 이에 유아는 상호작용 에 능동적으로 참여하면서 자신의 의사소통 행동이나 언어 표현에
대한 피드백을 얻고, 새로운 어휘나 언어적 표현들을 습득해 나간 다. 따라서 어머니가 유아가 표현하는 의사소통 의도를 지지하고, 언어발달 수준을 고려한 언어적 자극을 제공한다면, 유아의 의사 소통 행동에 긍정적인 영향을 미치는 것으로 해석할 수 있다.

또한, 어머니의 피드백과 유아의 언급하기 간의 정적 상관도 확 인할 수 있었는데, 이러한 피드백은 유아의 행동에 수반되는 것으 로 유아의 언어와 의사소통 행동에 어머니가 반응하고 적극적으로 상호작용하고 있음을 보여준다. 어머니의 표현하기와 유아의 무반 응 간에 나타난 정적 상관을 살펴보면, 표현적인 유형의 어머니에게 서 빈번하게 나타난 표현하기 유형은 유아의 언어적, 비언어적 행동 에 대해 어머니가 칭찬이나 감사, 인사와 같은 관습적 표현이 뒤따 르는 행동이었으므로 당연한 결과로 해석하였다.

마지막으로, 표현적 어머니의 언어적 입력 유형과 유아의 언어능 력 간의 관계를 살펴본 결과, 어머니의 주의환기와 유아의 SELSI 점 수에서 부적 상관이 나타났다. 이는 상황 맥락을 고려하지 않고 어 머니가 유아의 언어나 행동을 제지하기 위하여 일방적으로 제공하 는 주의환기와 같은 입력 형태는 유아의 언어발달에 부정적인 영향 을 미칠 수 있으며, 위에서 살펴본 주의환기와 유아의 무반응 간의 상관과 같은 맥락으로 해석할 수 있을 것이다. 이러한 결과는 어머 니가 사용하는 의사소통 전략에 따라 유아의 언어능력과 의사소 통 행동이 달라질 수 있음을 의미한다. 지시적인 유형의 어머니의 경우 SELSI 점수가 더 높은 상관을 보였으며, 이는 어머니가 유아에 게 직접적인 언어 행동을 요구하고, 말할 기회를 반복적으로 제공 함으로써 언어 습득을 촉진하는데 긍정적인 영향을 미친 것으로 해석할 수 있다. 그러나 유아의 의사소통은 반응하기만 유의한 상 관을 보였는데, 이는 어머니가 상호작용 상황을 주도하여 유아가 의사소통의 능동적인 주체가 아닌 반응의 역할인 것으로 해석해 볼 수 있다. 이는 어머니가 지시적이고 통제적인 언어전략만을 사 용하는 것보다 아동의 언어를 반복하거나 확장해주고 확대해주는 것과 같은 반응적 방식이 더욱 긍정적이라는 견해와도 일치한다 (Hart \& Risley, 1992).

표현적 유형 어머니 유아의 경우에는 언어능력에서는 유의한 상 관은 나타나지 않았으나, 여러 유형의 의사소통 행동에서 상관이 나타났다. 이들 어머니는 유아의 의사소통 의도를 존중하여 유아 에게 다양한 반응 기회를 제공하였다. 또한 어머니가 유아의 행동 과 감정들을 지지하고 적절한 수준의 언어적 자극을 풍부하게 제 공하여, 자발적인 의사소통 행동을 촉진하는 데 긍정적 영향을 미 치는 것으로 해석할 수 있다. 이는 유아의 자발적 언급하기, 반응하 기, 요구하기 등 의사소통 시작하기가 증가하였다는 견해와도 일치 하였다(Kim, 2003). 
요약하면, 유아에게 제공하는 언어적 입력의 형태가 어머니 중심 인 '지시' 또는 유아 중심인 '표현'의 일관된 한가지 형태로 제공되기 보다는 적절하게 조화를 이루어 제공될 때 언어능력과 의사소통 행동 발달에 더욱 효과적인 것으로 보인다. 즉, 이러한 결과는 어머 니와 유아는 서로에게 영향을 미치는 양방향적 관계이나 의사소통 에서 수행하는 각자의 역할은 서로 다를 수 있음을 시사한다.

최근 영유아기 연구들에서는(Kim \& Lee, 2007; Lee \& Song, 2008; Park, 2015) 부모나 가족접근의 중요성이 대두되고 있는 상황이므 로, 부모 교육은 영유아의 언어장애를 예방하고 조기 선별 및 중재 에 도움을 줄 수 있는 필수 항목이다. 유아는 의사소통 결함으로 일 상생활에서의 모든 경험에 영향을 받고, 이는 이후 사회적, 정서적, 학업적 그리고 직업적 어려움과 함께 심각한 부적응으로 연결될 수 도 있다(Im \& Jeong, 2010). 따라서, 영유아 시기의 언어적 결함을 조기에 발견하고 적절한 언어적 자극과 중재를 제공하는 것은 무엇 보다도 중요하다고 할 수 있으며, 특히 언어발달 결함의 조기 선별 및 중재 효과는 자녀와상호작용하는 어머니의 언어적 입력 유형과 많은 관련이 있다(Kim \& Hong, 2008; Paul \& Norbury, 2012). 이러 한 관점에서 본 연구의 결과는 어머니의 언어적 입력 유형과 유아 의 의사소통 행동 및 언어능력 간에 밀접한 관련이 있음을 기반으 로, 영유아기 언어장애위험군 유아의 조기 평가와 선별 과정에서 유아의 의사소통 행동에 영향을 미치는 요인을 파악할 수 있는 방 법의 하나로 상호작용 맥락을 고려한 어머니의 언어적 입력 유형을 포함시켜야 한다는 것을 시사한다. 또한 어머니와 유아의 상호작용 평가에서 어머니를 통해 유아의 의사소통 발달을 예측할 수 있고 이후의 양육태도에 대한 방향 등도 함께 논의해 볼 수 있다는 것을 보여준다.

본 연구는 어머니의 언어적 입력 유형에 따른 18-24개월 유아의 의사소통 행동과 언어 능력 간에 차이가 있는지를 알아보고, 기존 연구들과 달리 언어적 입력의 유형을 지시적과 표현적 두 가지로 구분하여 분석하였다는 데 차별성이 있다. 어머니의 언어적 입력 유형에 따른 유아의 의사소통 간에 유의미한 차이는 나타나지 않 았지만 각 상황에 따라 어머니가 선호하는 의사소통 형태가 두드 러졌으며, 지시적, 표현적 유형에 따른 어머니-유아 간의 의사소통 특성과 상관을 살펴보았다는 데 본 연구의 의의가 있다. 또한 표현 적 유형 어머니의 유아가 보인 의사소통 행동의 유형이 더욱 다양 하게 나타난 것으로 보아, 영유아 시기에는 어머니가 유아의 의사 소통 의도를 읽고 민감하게 반응하는 유아 중심의 언어적 입력 형 태가 유아의 언어 능력에 긍정적 영향을 미칠 수 있음을 간접적으 로 확인할 수 있었다. 또한, 어머니의 지시적, 표현적 유형에 따른 유 아의 의사소통 행동 간의 상관을 자세히 분석함으로써, 어머니가
유아의 의사소통 의도에 민감하게 반응하면서 지시적인 형태와 표 현적인 형태의 언어적 자극을 적절하게 조화를 이루어 제공할 때 유아의 의사소통 행동에 긍정적인 영향을 미칠 수 있음을 확인하 였다.

초기 발달에서는 무엇보다 어머니-유아 간의 상호작용이 의사소 통과 언어발달의 예후를 예측하는 중요한 지표가 되므로, 특히 이 러한 상호작용에 영향을 미치는 상황 맥락과 어머니의 언어적 자 극 형태를 고려해야 한다. 하지만, 본 연구에서는 책 읽기와 놀이 상 황 각각에서 어머니-유아 간의 의사소통 특성과 유형을 세부적으 로 분석하지 못했다는 한계가 있다. 또한 언어 입력에 따른 유아의 반응을 언어적 행동과 비언어적 행동 모두를 포함하여 분석하였지 만 전체 빈도만을 제시하였으므로 이후에는 각각의 행동 특성에 대한 내용분석이 이어져야 할 것이다. 또한, 후속 연구에서는 종단 적 관찰을 통해 어머니의 언어적 입력 형태의 변화에 따른 유아의 말하기 유형 간의 관계를 살펴볼 필요가 있을 것이다. 또한 이를 바 탕으로 임상 현장에서 말 늦은 유아(late talker)와 언어발달지연 영 유아에게 적절한 언어 자극 형태를 파악하고 이를 어머니가 유아 에게 제시하도록 돕는 부모 교육 근거 마련도 필요할 것이다.

\section{REFERENCES}

Chang-Song, Y. K. (2004). Early lexical development of Korean infants: 8-17 months. Korean Journal Psychology, 23, 77-99.

Choi, E. J., \& Hyun, E. J. (2002). Verbal and non-verbal interaction between mother and 1 year old infant during picture book reading. Journal of Children's Literature and Education, 3, 127-154.

Della Corte, M., Benedict, H., \& Klein, D. (1983). The relationship of pragmatic dimensions of mothers' speech to the referential-expressive distinction. Journal of Child Language, 10, 35-43.

Hart, B., \& Risley, T. R. (1992). American parenting of language-learning children: persisting differences in family-child interactions observed in natural home environments. Developmental Psychology, 28, 1096-1105.

Hong, G. H. (2009). Analyses of mother-related variables in mother-child interaction for predicting expressive vocabulary development in children. Journal of Speech \& Hearing Disorders, 18, 35-49.

Im, E. J., \& Jeong, M. J. (2010). Variables related to behavior problems of children with communication disorders. Korean Journal of Communication Disorders, 15, 79-93.

Jang, H. S., Seo, S. J., \& Ha, J. Y. (2011). Developmental assessment for the early intervention program planning. Seoul: Hakjisa. 
Gyu Ri Kim, et al. • Effective of Language Input Type on Communicative and Language Ability of Toddlers

Kim, E. K. (2003). The effect of parent education on communicative behaviors of toddlers with language delay. Korean Journal of Early Childhood Special Education, 3, 177-204.

Kim, J. M., \& Hong, G. H. (2008). Research trends regarding infancy and toddlerhood language impairment during the last 10 years. Korean Journal of Communication Disorders, 13, 565-593.

Kim, J. M., \& Lee, S. H. (2007). The effect of "It Takes Two to Talk" program on communicative abilities of the children with developmental language delay and their parents' behaviors. Korean Journal of Communication Disorders, 12, 607-624.

Kim, J. M., \& Mahoney, G. (2004). The effects of mother's style of interaction on children's engagement: implications for using responsive interventions with parents. Topics in Early Childhood Special Education, 24, 31-38.

Kim, R. Y., Lee, H. J., \& Lee, Y. K. (2015). The effect of book reading and play situations on the communicative acts of late-talking toddlers and their mothers. Journal of Speech-Language \& Hearing Disorders, 24, 15-27.

Kim, Y. S., \& Kwak, K. J. (2010). The relationship between maternal verbal responsiveness, infant's social communication ability during infancy and language ability in early childhood. Korean Journal of the Human Development, 17, 191-207.

Kim, Y. T., Kim, K. H., Yoon, H. R., \& Kim, H. S. (2003). Sequenced Language Scale for Infants (SELSI). Seoul: Special Education Publishing.

Kitamura, C., \& Burnham, D. (2003). Pitch and communicative intent in mother's speech: adjustments for age and sex in the first year. Infancy, 4, 85-110.

Klein, M. D. (1980). Expressive and referential communication in children's early language development: the relationship to mothers' communicative styles (Doctoral dissertation). Michigan State University, Ann Arbor, MI.

Ko, J. M., \& Kim, H. J. (2015). The effects on the mother' perceived power, the mother' and toddler' temperature, their interaction on the responsiveness between mother and her two-year-old child. Korean Journal of Early Childhood Education, 35, 175-203.

Lee, J., Lee, K., \& Chang, Y. (2004). The effect of maternal verbal interaction style on infants' early vocabulary development during picture book reading. Korean Journal of Development Psychology, 17, 131-146.

Lee, K., \& Song, J. (2008). The effects of small group parent education program for the interaction behavior between the mothers and their young children with developmental delays and the language abilities of young children. Korean Journal of Special Education, 42, 1-25.

Lee, Y. (2011). The relationships among language, communicative abilities and motor, cognitive, and socio-emotional development in toddlers with language delays. Korean Journal of Communication Disorders, 16, 1-12.

Lee, Y. K., \& Seol, A. (2012). Maternal communication style of toddlers with developmental language delay during toddler-mother interaction. Korean Journal of Communication Disorders, 17, 263-273.

Ludden, D. (2016). The psychology of language: an integrated approach. Thousand Oaks, CA: SAGE.

Nelson, K. (1973). Structure and strategy in learning to talk. Monographs of the Society for Research in Child Development, 38, 1-135.

Pae, S., \& Kwak, K. C. (2011). Korean MacArthur-Bates Communicative Development Inventories (K M-B CDI): user's guide and technical manual. Seoul: Mindpress.

Park, S. M., \& Jo, H. S. (2008). Maternal conversation strategies in motherchild interactions and infants' early vocabulary development: focused on the contextual effects. Journal of Future Early Childhood Education, 15, 177204.

Park, W. J. (2015). Effect of parental education using smartphone application on the number of utterances and interaction skills of children with language delay and their parents (Master's thesis). Ewha Womans University, Seoul, Korea.

Paul, R., \& Norbury, C. (2012). Language disorders from infancy through adolescence: listening, speaking, reading, writing, and communicating (4th ed.). St. Louis, MO: Elsevier.

Sénéchal, M., Cornell, E. H., \& Broda, L. S. (1995). Age-related differences in the organization of parent-infant interactions during picture-book reading. Early Childhood Research Quarterly, 10, 317-337.

Shin, G. H., \& Kim, C. B. (2013). Individual differences in performance on working memory tasks according to object, spatial, and verbal cognitive styles. Korean Journal of Cognitive and Biological Psychology, 25, 539-563.

Sung, M. (2003). Maternal conversation style and communicative intent of young children during free play. Korean Journal of Child Studies, 25, 77-89.

Toth, K., Munson, J., Meltzoff, A. N., \& Dawson, G. (2006). Early predictors of communication development in young children with autism spectrum disorder: joint attention, imitation, and toy play. Journal of Autism and Developmental Disorders, 36, 993-1005.

Vaala, S. E., Linebarger, D. L., Fenstermacher, S. K., Tedone, A., Brey, E., Barr, R., ... \& Calvert, S. L. (2010). Content analysis of language-promoting teaching strategies used in infant-directed media. Infant and Child Development, 19, 628-648. 
Appendix 1. Maternal linguistic input type

\begin{tabular}{|c|c|c|}
\hline & 정의 & 예 \\
\hline 주의환기 & 유아의 주의를 끌기 위한 행동으로, 유아의 이름을 부르거나 ‘이거(여기) 봐라’와 같은 지시를 포함한다. & $\begin{array}{l}\text { 유아 이름 부르기. } \\
\text { - 이거(여기) 봐라 }\end{array}$ \\
\hline 명명하기 & 사람이나 대상 또는 동작 및 상황의 이름을 말하거나 붙여 주는 것이며, 지시적인 대명사와 함께 사용 될 수 있다. & $\begin{array}{l}\text { - 할머니 } \\
\text { - 공이야 } \\
\text { - 보다. 이건 보다. } \\
\text { - 먹다. }\end{array}$ \\
\hline 지시하기 & $\begin{array}{l}\text { 유아에게 반응을 이끌어내는 것으로 정보를 요구하거나 직접적 인 행동 또는 언어적 표현을 요청, 지시하는 행동을 } \\
\text { 포함한다. }\end{array}$ & $\begin{array}{l}\text { 이거 누구야? } \\
\text { - 토끼. 따라 해봐. } \\
\text { - 여기 앉아. }\end{array}$ \\
\hline 설명하기 & $\begin{array}{l}\text { 즉각적인 상황에서 대상이나 유아의 행동, 감정 그리고 주관적인 생각 또는 사실을 표현해주거나 과거나 미래의 } \\
\text { 사건을 서술해주는 것을 포함한다. }\end{array}$ & $\begin{array}{l}\text { - OO이가 물 가져 왔네. } \\
\text { - 늑대 무서워. } \\
\text { - 손에 묻었어. } \\
\text { - 할머니 집에서 개미 봤지 } \\
\text { - 이거 정말 재미있다. } \\
\text { - 이모 나중에 와. }\end{array}$ \\
\hline 피드백 & 유아의 말이나 행동에 대해 반응해 주는 것으로 칭찬, 대답, 명료화 요구, 확인, 모방, 수정 등을 포함한다. & $\begin{array}{l}\text { - 정말 잘했어. } \\
\text { - 이건 코끼리야. } \\
\text { - 응? 멍멍이라고? } \\
\text { - 아 이건 생쥐구나. } \\
\text { - 응. 개미 } \\
\text { - 이건 생쥐 아니고 개미. }\end{array}$ \\
\hline 표현하기 & 사회적인 상황에서 사용하는 관습적인 말을 표현하는 것을 포함한다. & $\begin{array}{l}\text { - 안녕하세요 } \\
\text { - 고맙습니다 } \\
\text { - 미안해 }\end{array}$ \\
\hline
\end{tabular}

Appendix 2. Toddler's communicative behaviors (Lee \& Seol, 2012)

\begin{tabular}{|c|c|c|}
\hline & 정의 & 예 \\
\hline 언급하기 & 대상이나 사물의 이름을 말하거나 주관적인 생각, 사실을 표현 하는 행동. & $\begin{array}{l}\text { - 멍멍. } \\
\text { - 이거 딸기. } \\
\text { - 주세요. } \\
\text { - 아까 몬욕했어. } \\
\text { - 깜짝 놀랬어. } \\
\text { - 나 할 줄 몰라 } \\
\text { - 짹짹 새야. }\end{array}$ \\
\hline 요구하기 & 필요한 사물이나 행동을 요구하는 언어적 또는 비언어적인 행동. & $\begin{array}{l}\text { - 주세요. } \\
\text { - 엄마 열어줘. }\end{array}$ \\
\hline 모방하기 & 어머니의 발화를 완전하게 혹은 따라 하는 행동 & - 책(엄마)-책(유아) \\
\hline 질문하기 & 어머니의 대답이나 반응을 요구하는 행동. & - 이거 뭐야? \\
\hline 반응하기 & 어머니의 언어적 혹은 비언어적 행동에 대한 반응. & $\begin{array}{l}\text { - 응(네) } \\
\text { - 엄마 아니야. 생쥐. } \\
\text { - 거부하기. }\end{array}$ \\
\hline 무반응 & 어머니의 행동에 대하여 반응하지 않는 경우. & \\
\hline
\end{tabular}


Gyu Ri Kim, et al. • Effective of Language Input Type on Communicative and Language Ability of Toddlers

\section{국문초록}

\section{어머니의 언어적 입력 유형이 18-24개월 유아의 의사소통 행동과 언어능력에 미치는 영향}

김규리 ${ }^{1} \cdot$ 이희란 ${ }^{2}$

부산가톨릭대학교 대학원 언어청각치료학과, ${ }^{2}$ 부산가톨릭대학교 언어청각치료학과

배경 및 목적: 본 연구에서는 18-24개월 유아의 의사소통 행동과 언어능력에 영향을 미치는 어머니의 언어적 입력 유형을 분류하고, 유 형 집단에 따른 차이와 상관을 살펴보고자 하였다. 방법: 연구 대상은 언어를 포함한 전반적인 발달이 정상범주에 속하는 만18-24개월 일반 유아 20 명과 그 어머니 20 명으로 총 40 명이었다. 놀이와 책 읽기 상황에서 어머니-유아의 상호작용을 녹화하여 전사하였으며, 어 머니의 언어적 입력 유형과 유아의 의사소통 행동의 빈도를 측정하여 전체 발화로 나눈 비율로 분석하였으며, 유아의 언어능력은 SELSI 와 K M-B CDI 평가 결과로 비교하였다. 결과: 어머니의 언어적 입력 유형 집단별 유아의 의사소통 행동 간에 유의미한 차이는 나타나 지 않았으나 SELSI 점수에서 지시적 유형 어머니의 유아가 높은 점수를 보였다. 지시적인 유형 어머니와 유아의 의사소통 행동은 지시반응, 표현-반응에서 정적인 상관관계를 보였으며, 표현적인 유형 어머니와 유아의 의사소통 행동은 주의환기-무반응, 지시-언급, 지시반응, 설명-요구, 설명-반응, 피드백-언급, 표현-무반응에서 정적인 상관관계를 보였다. 논의 및 결론: 본 연구를 통해 어머니의 의사소통 유형에 따른 언어 입력 분석의 필요성을 확인할 수 있었으며, 이러한 결과는 어머니 입력 유형별로 유아의 반응성과의 관련성을 심층 검 토할 필요가 있음을 시사한다. 특히, 언어장애위험군 영유아의 조기 선별과 부모교육에의 활용 필요성을 함께 논의하였다

핵심어: 어머니의 언어적 입력 유형, 의사소통 행동, 언어능력, 언어발달

본 연구는 제 1 저자의 석사학위 논문을 요약한 것임.

\section{참고문헌}

고지민, 김희진(2015). 힘과 통제에 대한 어머니의 인식, 기질 및 상호작용이 어머니와 만 2세 자녀의 반응성에 미치는 영향. 유아교육연구, 35, 175203.

김란영, 이효주, 이윤경(2015). 책 읽기와 놀이 조건이 말 늦은 영유아와 어머니의 의사소통 행동에 미치는 영향. 언어치료연구, 24, 15-27.

김연수, 곽금주(2010). 영아기 어머니의 언어적 반응성 및 영아의 비언어적 의사소통능력과 아동 초기 언어능력간의 관계. 인간발달연구, $17,191-207$. 김영태, 김경희, 윤혜련, 김화수(2003). 영유아 언어발달 검사(SELSI). 서울: 도서출판 특수교육.

김은경(2003). 부모교육이 언어발달지체유아의 의사소통 행동 변화에 미치는 영향: 환경중심 언어중재와 아동중심 언어중재를 중심으로. 유아특수 교육연구, 3, 177-204.

김정미, 이수향(2007). "It Takes Two to Talk" 부모 교육 프로그램이 언어발달지체아동의 의사소통과 부모의 행동에 미치는 효과. 언어청각장애연

구, 12, 607-624.

김정미, 홍경훈(2008). 영유아기 언어장애의 연구동향: 최근 10년간을 중심으로. 언어청각장애연구, 13, 565-593.

박선미, 조희숙(2008). 어머니-영아간 상호작용 맥락에 따른 어머니의 대화전략 유형과 영아의 초기 어휘발달. 미래유아교육학회지, 15, $177-204$.

박원정(2015). 발화분석 어플리케이션을 활용한 상호작용 증진 부모교육이 언어발달지연 아동과 부모의 발화 및 상호작용 기술에 미치는 영향. 이화 여자대학교 석사학위논문.

배소영, 곽금주(2011). 맥아더-베이츠 의사소통발달평가 전문가 지침서. 서울: 마인드프레스.

성미영(2003). 자유놀이 상황에 나타난 어머니의 대화 양식과 유아의 의사소통 의도. 유아학회지, 25, 77-89.

신경희, 김초복(2013). 대상, 공간 및 언어 인지 양식에 따른 작업기억 과제 수행의 개인차. 한국심리학회지: 인지 및 생물, 25, 539-563.

이금진, 송준만(2008). 소집단 부모참여프로그램이 어머니와 발달지체 영유아의 상호작용행동 및 영유아의 언어능력에 미치는 영향. 특수교육학연 구, 42, 1-25. 
이윤경(2011). 언어발달지체 영유아의 언어 및 의사소통 능력과 인지, 운동 및 사회성 발달과의 관계. 언어청각장애연구, 16, 1-12.

이윤경, 설아영(2012). 영유아-어머니 상호작용에서의 언어발달지체 영유아 어머니 의사소통 행동 특성. 언어청각장애연구, 17, 263-273.

이지연, 이근영, 장유경(2004). 어머니의 책 읽기 상호작용 유형이 영아의 초기 어휘발달에 미치는 영향. 한국심리학회지: 발달, 17, 131-146.

임은주, 정문자(2010). 의사소통 장애 아동의 문제행동에 영향을 미치는 요인. 언어청각장애연구, 15, 79-93.

장유경(2004). 한국 영아의 초기 어휘발달: 8-17개월. 한국심리학회지: 일반, 23, 77-99.

장혜성, 서소정, 하지영(2011). 영아선별 교육진단검사 전문가지침서. 서울: 학지사.

최은주, 현은자(2002). 책읽기 활동에서 나타나는 어머니와 1 세 영아의 상호작용: 월령과 책의 종류에 따른 비교. 어린이문학교육연구, 3, 127-154.

홍경훈(2009). 아동의 초기 표현어휘발달에 영향을 미치는 엄마의 상호작용 요인 분석. 언어치료연구, 18, 35-49. 